\title{
Numerical Simulation of Dynamic Response of Submerged Floating Tunnel under Regular Wave Conditions
}

\author{
Wenlong Luo, ${ }^{1,2}$ Bo Huang $\mathbb{D},{ }^{1,2}$ Yao Tang, ${ }^{1,2}$ Hao Ding $\mathbb{D}^{3}{ }^{3}$ Ke Li, ${ }^{3}$ Liang Cheng $\left(\mathbb{D},{ }^{3}\right.$ \\ and Qingyang Ren ${ }^{1,2}$ \\ ${ }^{1}$ State Key Laboratory of Mountain Bridge and Tunnel Engineering, Chongqing Jiaotong University, Chongqing 400074, China \\ ${ }^{2}$ School of Civil Engineering, Chongqing Jiaotong University, Chongqing 400074, China \\ ${ }^{3}$ China Merchants Chongqing Communications Technology Research and Design Institute Co., Ltd., Chongqing, 400067, China
}

Correspondence should be addressed to Bo Huang; bohuang@cqjtu.edu.cn

Received 19 November 2021; Accepted 24 December 2021; Published 4 January 2022

Academic Editor: Traian Mazilu

Copyright (c) 2022 Wenlong Luo et al. This is an open access article distributed under the Creative Commons Attribution License, which permits unrestricted use, distribution, and reproduction in any medium, provided the original work is properly cited.

A submerged floating tunnel (SFT) is considered an innovative alternative to conventional bridges and underground or immersed tunnels for passing through deep water. Assessment of hydrodynamic performance of SFT under regular wave loading is one of the important factors in the design of SFT structure. In this paper, a theoretical hydrodynamic model is developed to describe the coupled dynamic response of an SFT and mooring lines under regular waves. In this model, wave-induced hydrodynamic loads are estimated by the Morison equation for a moving object, and the simplified governing differential equation of the tunnel with mooring cables is solved using the fourth-order Runge-Kutta and Adams numerical method. The numerical results are successfully validated by direct comparison against published experimental data. On this basis, the effects of the parameters such as the cable length, buoyancy-weight ratio, wave period, wave steepness, and water/submergence depth on the dynamic response of the SFT under wave loading are studied. The results show that tunnel motions and cable tensions grow with wave height and period and decrease with submergence depth. The resonance of the tunnel will be triggered when the wave period is close to its natural vibration period, and the estimation formula of wave period corresponding to tunnel resonance is proposed in this paper.

\section{Introduction}

The submerged floating tunnel (SFT), also known as Archimedes Bridge, is considered as an innovative alternative to conventional bridges and underground or immersed tunnels for passing through waterways, lakes, and rivers. A typical SFT is composed of four major parts: (1) the hollow tunnel tube which is made up of tunnel segments and allows traffics and pedestrians to get through; (2) the offshore connections between the tunnel and mainland on the ends; (3) the supporting systems like anchor cables or pontoons to balance the redundant buoyancy of the SFT tube; and (4) the foundation structures which are constructed at the waterbed to install cable systems $[1,2]$. Compared to traditional sea-crossing projects, such as longspan bridges and immersed tube tunnels, the SFT with mooring cables has such advantages as the following: (1) strong adaptability of underwater foundation; (2) the construction cost per unit length is almost the same regardless of tunnel length; and (3) even in severe weather conditions, there is little impact on normal vehicle traffic and other water production activities $[3,4]$.

The first idea of the SFT can be traced back to the first decades of the Twentieth Century in Norway. Since the 1980 s, the SFT has gradually attracted the attention of science and technology circles and governments in Europe, the United States, China, and Japan because of its unique engineering advantages and great commercial value. The first international conference devoted solely to the topic of submerged floating tunnels was held in Sandnes, Norway, in June 1996, attended by nearly 100 experts and engineers [5-7]. The Sino-Italian Joint Laboratory for Archimedes Bridge (SIJLAB) has been created in 2004, whose principal purpose is the design and 
realization of the first SFT prototype in the world, planned in Qiandao Lake [8].

Despite these efforts, the first construction of the SFT is not realized yet, and more extensive research studies are needed. In the past 20 years, a large number of scholars had begun to pay more attention to the dynamic problems of SFT under special conditions such as waves, currents, earthquakes, tsunamis, collisions, cables breakage, and so on. Xiang et al. [2, 9-11] simplified the model of SFT by using the mathematical analogy method as a beam on an elastic foundation and investigated the global dynamic response of the SFT subjected to different environmental conditions such as external impact, cable break, and vehicle passage. For engineering structures, earthquake is a common emergency. Therefore, many scholars such as Pilato et al., Martinelli et al., Wu et al., and Xie et al. [12-16] studied the dynamic response of SFT under earthquake excitation through theoretical analysis or finite element simulation. Sun et al. $[17,18]$ studied the vibration characteristics of tension legs of the SFT under random excitation. Seo et al. [19] proposed a formula based on experimental data to describe the shock waves and impulse pressures generated by an explosive away from the SFT in order to investigate the dynamic response of the SFT subjected to the underwater explosion. Xiang et al. [20] summarized the main content of risk analysis of SFT and classified the risk management into six stages. At the same time, the environmental risk assessment was carried out with the SFT prototype in Qiandao Lake as an example. $\mathrm{Lu}$ et al. [21] analyzed SFT dynamics when going through tether slacking and the related snap force under wave conditions. Jin et al. [22] developed a time-domain coupled hydroelastic dynamics model to solve the tunnel-mooringtrain interaction under wave excitations for investigating the interaction between the tunnel and the train. Luo et al. [23] established a model of the SFT impacted by the submarine based on the principles of the smoothed particle hydrodynamics and finite element method to analyze the variation relationship of related physical quantities of the submarine and tunnel.

Loads on the SFT except for gravity, in general, mainly come from the fluid around the tunnel. Therefore, the fluidstructure interaction between the tunnel and water should be further studied. Kunish [24] investigated the wave force characteristics acting on the SFT. Chao [25] studied the fluid-structure interaction response of the mooring cable and tested the hydrodynamic coefficient of the mooring cable through the flume experiment. Oh et al. [26] studied the dynamic response of the SFT with the vertical and inclined mooring cable under the action of regular waves through the physical experimental method. Based on $\mathrm{Oh}$ et al.'s experiment, Cifuentes et al. [27] established a numerical analysis model by using finite element software OrcaFlex and CHARM3D and further analyzed the influence of different parameters for the dynamic response of the SFT. Yang et al. [28] also completed a series of systematic 2D experiments to investigate the motion characteristics of the SFT. Seo et al. [29] proposed a simple but accurate theoretical method to estimate hydrodynamic forces of the SFT and tests with physical models in a wave flume carried out for verification. Paik et al. and Ge et al. [30, 31] performed analyses on the fluid-structure interaction of SFT in the wave field by the boundary element method applying potential theory and investigated dynamic response characteristics of SFT. Chen et al. [32] presented a numerical model for analyzing the nonlinear interaction between the moored SFT and surface waves and especially investigated the influence of buoyancy-weight ratio on the SFT dynamic response. Zou et al. [33] simulated the oceanic internal solitary wave's generation and propagation using the CFD software Fluent to study the mechanism of interaction between the internal solitary wave and the SFT.

As seen earlier, physical experiments and numerical simulation are currently the two main methods of studying science and engineering problems. Although the results of physics experiments are often more convincing, sometimes the experiments are too expensive to be repeated many times. At this point, numerical simulation methods are needed to assist the analysis. However, in the past studies, both experimental methods and numerical simulation methods were often limited by experimental cost or calculation time, resulting in a small amount of data. Thus, it was difficult to reflect the details of the changes of the relevant characteristic physical quantities. In addition, the dynamic response of the SFT with vertical mooring cable under regular wave loads has not been studied deeply enough. Therefore, this paper will simplify the actual SFT with the vertical mooring cable model, focusing on the main influencing factors and ignoring the secondary influencing factors as much as possible to ensure the efficiency of calculation. At the same time, the simplified theoretical model is proposed and the efficient calculation is carried out by the numerical method. To ensure the reliability of the theoretical model, the calculated results are compared with the existing physical experimental data. On this basis, the relationship between SFT dynamic response and physical parameters is described with dense data points, and the fluid-structure interaction between the SFT and wave is analyzed.

\section{Physical Experiments}

In 2013, Oh et al. [26] completed a hydrodynamic experiment of SFT. In that study, the dynamic response of a single SFT under wave loading was analyzed. The SFT model was installed in a wave tank of $53 \mathrm{~m}$ long, $1.25 \mathrm{~m}$ high, and $1 \mathrm{~m}$ wide and confined by vertical mooring cables that were fixed to the tank floor bottom. The size of the model was determined to be $1 / 100$ of the prototype structure. The SFT model was $0.098 \mathrm{~m}$ in length and $0.023 \mathrm{~m}$ in cross section diameter, and its highest point was $0.05 \mathrm{~m}$ above the bottom of the tank in Figure 1. The ends of the mooring cable were connected to the load cells to measure the exact tension of the tension legs. The motion tracking devices followed the displacements of two targets on the tube body to obtain accurate measurements of motions. Meanwhile, eight pressure gauges were attached along the central cross section of the SFT model for obtaining the pressure on the structure due to the regular wave action. 


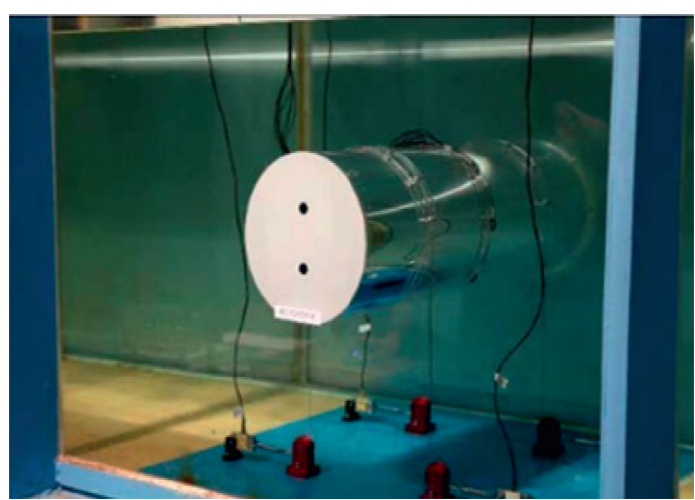

(a)

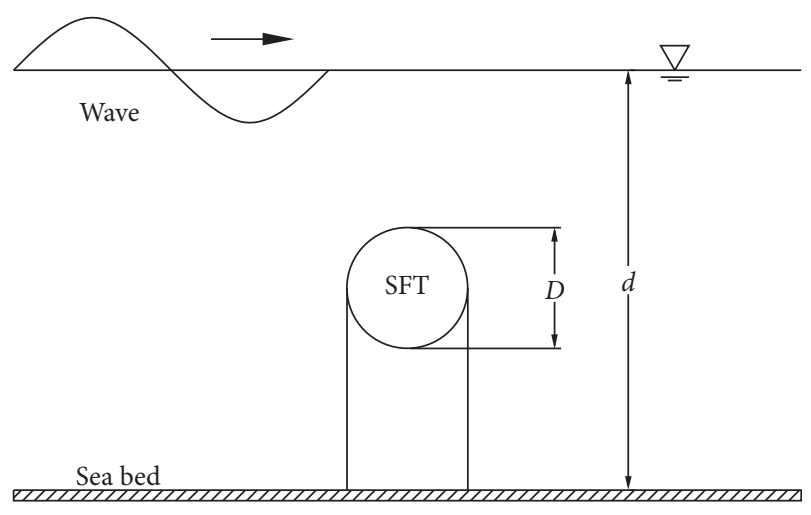

(b)

Figure 1: (a) Experimental configuration (Cifuentes et al. [27]). (b) Diagram and definition of the parameters of the SFT.

In that experiment, waves were generated for 60 seconds for each test condition. By changing the parameters of the wave and SFT model which is given in Table 1, the dynamic characteristics of the SFT were revealed with the parameters change. The main results of this study are the displacement of the tube and forces on the mooring cable. More details about the experiment are given in Oh et al. [26]. The experimental results will be used to verify the numerical results in this paper.

\section{Description of Mathematical Models}

3.1. Basic Assumption and Simplified Model. According to the experimental model of Oh et al. [26], the following basic assumptions are made before the mathematical model is established:

(1) Due to the ratio of length to the diameter of the tunnel model being relatively small and the lack of constraints at both ends of the tunnel model, the rigid body displacement of the tube is far greater than its deformation, so the tube is taken as a rigid body. It can be seen from the experimental results of Oh et al. [26] that the rotation of the tube is extremely small, so the rotation of the tube is ignored. Therefore, the displacement of the tube can be completely expressed by the coordinates of the central point of the tunnel.

(2) Because the fluid-structure interaction between the tube and the wave is extremely complex, it is difficult to accurately calculate the wave forces on the tube. The wave force on the tube is given by the Morison equation, which is an empirical formula proposed by Morison et al. [34] in 1950. Morison equation is mostly used because of its proven accuracy in application to offshore structures. Xiang et al. [35] proposed the layered integration method based on the Morison equation, which considered the variation of velocity and acceleration distribution of fluid particles in the altitude direction. The method is used to calculate the wave forces of complex structures with relatively large cross sections. However, the
TABLE 1: Summary of the experimental conditions.

\begin{tabular}{lc}
\hline Parameter & Values \\
\hline Diameter $(\mathrm{m})$ & 23 \\
Water depth $(\mathrm{m})$ & $65-80-95$ \\
Buoyancy-to-weight ratio & $2.2-2.6-3.0$ \\
Wave period (seconds) & $6.5-8.0-10.0-13.0$ \\
Wave steepness & $0.013-0.027-0.040-0.053$ \\
\hline
\end{tabular}

tunnel section of the model discussed in this paper is small, so this paper will use the original Morison equation to calculate the wave force on the SFT.

(3) Because the elastic modulus of the mooring cable is very large, the tube displacement caused by cable deformation is much smaller than that caused by the wave load. Therefore, the deformation of the mooring cable under the wave load is not considered; that is, the length of the anchor cable is constant. At the same time, since the diameter of the mooring cable is much smaller than that of the tube, the wave force on the mooring cable is ignored.

(4) According to assumptions (1) and (3), the four anchor cables on both sides of the pipe body are approximately equivalent to one anchor cable, whose axis passes through the center of the tunnel section. Considering the actual situation, the wave force is generally far less than the residual buoyancy of the tube, so the mooring cable force is always present.

Based on the above assumptions, the experimental model, as shown in Figure 2, can be viewed as an inverted pendulum. The tube's movement can be described in the $\mathrm{X}$-Y plane that is vertical to the axis of the tube, taking the bottom end of the mooring cable as the origin of the coordinate system, the $X$-axis is parallel to the sea bed, and the $Y$-axis is perpendicular to it.

3.2. Establishment of the Mathematical Model. According to the Morison equation, the wave forces acting on the $X$ and $Y$ directions of the tube per unit tube axis length are given as follows: 


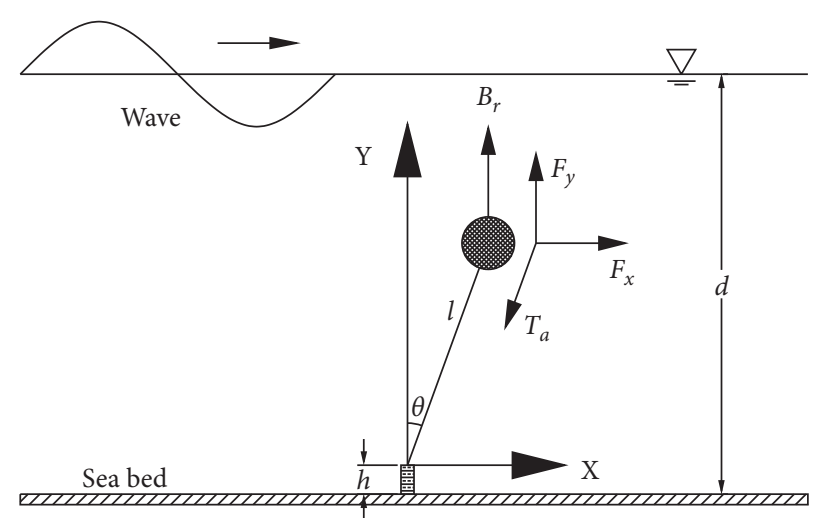

FIGURE 2: Simplified model of SFT.

$$
\left\{f_{x}=\frac{C_{D} \rho D}{2}\left(u_{x}-\dot{x}\right)\left|u_{x}-\dot{x}\right|+\frac{C_{M} \rho \pi D^{2}}{4} a_{x}-\frac{C_{m} \rho \pi D^{2}}{4} \ddot{x} f_{y}=\frac{C_{D} \rho D}{2}\left(u_{y}-\dot{y}\right)\left|u_{y}-\dot{y}\right|+\frac{C_{M} \rho \pi D^{2}}{4} a_{y}-\frac{C_{m} \rho \pi D^{2}}{4} \ddot{y}\right.
$$

$$
\begin{aligned}
& \left\{\begin{array}{l}
\dot{x}=l \dot{\theta} \cos \theta \\
\dot{y}=-l \dot{\theta} \sin \theta
\end{array}\right. \\
& \left\{\ddot{x}=l \ddot{\theta} \cos \theta-l \dot{\theta}^{2} \sin \theta \ddot{y}=-l \ddot{\theta} \sin \theta-l \dot{\theta}^{2} \cos \theta\right.
\end{aligned}
$$

Substituting (4) into (2) and (3), the formula of velocity and acceleration of the fluid particle at the axis of the tube in a polar coordinate system can be obtained as follows: the Airy wave theo particle at the axis of the tube are given by the following formula:

$$
\begin{aligned}
& \left\{\begin{array}{l}
u_{x}=\frac{\pi H}{T} \frac{\cosh k(y+h)}{\sinh k d} \cos (k x-\omega t+\varphi) \\
u_{y}=\frac{\pi H}{T} \frac{\sinh k(y+h)}{\sinh k d} \sin (k x-\omega t+\varphi)
\end{array}\right. \\
& \left\{\begin{array}{l}
a_{x}=\frac{2 \pi^{2} H}{T^{2}} \frac{\cosh k(y+h)}{\sinh k d} \sin (k x-\omega t+\varphi) \\
a_{y}=-\frac{2 \pi^{2} H}{T^{2}} \frac{\sinh k(y+h)}{\sinh k d} \cos (k x-\omega t+\varphi)
\end{array}\right.
\end{aligned}
$$

where $H$ is wave height, $T$ is wave period, $\omega=2 \pi / T, k=2 \pi /$ $L, L$ is the wavelength, $\varphi$ is circular frequency, $h$ is the height of pile caps, and $d$ is water depth. The above formulas are all based on Cartesian coordinates, which can be converted to polar coordinates for the convenience of calculation. The coordinate transform formula is as follows:

$$
\left\{\begin{array}{l}
x=l \sin \theta \\
y=l \cos \theta
\end{array}\right.
$$

where $l$ is mooring cable length and $\theta$ is the angle between the mooring cable and the $Y$-axis. The derivative of (4) with respect to time $t$ twice yields the following equation:

Let

$$
\left\{\begin{array}{l}
C_{1}=\frac{C_{D} \rho D}{2} \\
C_{2}=\frac{C_{M} \rho \pi D^{2}}{4} . \\
C_{3}=\frac{C_{m} \rho \pi D^{2}}{4}
\end{array}\right.
$$

Substituting equations (4)-(6) and (9) into (1), the wave forces acting on the $X$ and $Y$ directions of the tube per unit tube axis length in a polar coordinate system can be obtained as follows: 


$$
\left\{\begin{array}{l}
f_{x}=C_{1}\left(u_{x}-\dot{\theta} \cos \theta\right)\left|u_{x}-\dot{\theta} \cos \theta\right|+C_{2} a_{x}-C_{3}\left(\ddot{\theta} \cos \theta-l \dot{\theta}^{2} \sin \theta\right) \\
f_{y}=C_{2}\left(u_{y}+\dot{\theta} \sin \theta\right)\left|u_{y}+\dot{\theta} \sin \theta\right|+C_{2} a_{y}+C_{3}\left(\ddot{\theta} \sin \theta+\dot{\theta}^{2} \cos \theta\right)
\end{array},\right.
$$

where $u_{x}, u_{y}, a_{x}$, and $a_{y}$ are given in (7) and (8). To keep the formula simple, let

$$
\left\{\begin{array}{l}
f_{p x}=C_{1}\left(u_{x}-\dot{i \theta} \cos \theta\right)\left|u_{x}-\dot{\theta} \cos \theta\right|+C_{2} a_{x}+C_{3} \dot{\theta}^{2} \sin \theta \\
f_{p y}=C_{2}\left(u_{y}+i \dot{\theta} \sin \theta\right)\left|u_{y}+l \dot{\theta} \sin \theta\right|+C_{2} a_{y}+C_{3} \dot{\theta}^{2} \cos \theta
\end{array} .\right.
$$

Substituting (11) into equation (10), (10) can be converted to

$$
\left\{\begin{array}{l}
f_{x}=f_{p x}-C_{3} \ddot{\imath} \cos \theta \\
f_{y}=f_{p y}+C_{3} \ddot{\theta} \sin \theta
\end{array} .\right.
$$

According to the above formula, the dynamic equations, in the polar coordinate system, are presented in tangential and normal directions of the tube movement, respectively, as follows:

$$
\left\{\begin{array}{l}
\text { tangential: }-B_{r} \sin \theta-L f_{y} \sin \theta+L f_{x} \cos \theta=m \ddot{\theta} \\
\text { normal: } T_{a}-B_{r} \cos \theta-L f_{y} \cos \theta-L f_{x} \sin \theta=m l \dot{\theta}^{2}
\end{array},\right.
$$

where $L$ is the length of the tube, $B_{\mathrm{r}}$ is the buoyancy of the tube, and $T_{\mathrm{a}}$ is the tension of the anchor cable, tube. By substituting (12) into (13), solving the second derivative of $\theta$ with respect to time, and introducing initial conditions, the governing differential equation of the motion of the tube can be obtained:

$$
\left\{\begin{array}{l}
\ddot{\theta}=\frac{L f_{p x} \cos \theta-L f_{p y} \sin \theta-B_{r} \sin \theta}{l\left(C_{3} L+m\right)} \\
\theta(0)=0 ; \dot{\theta}(0)=0
\end{array},\right.
$$

where $m$ is the mass of the tube. The governing differential equation is a second-order nonlinear ordinary differential equation that can be solved by developing computer programs using the Runge-Kutta and Adams numerical method.

\section{Verification of Calculation Results}

As stated above, the displacements of the SFT and forces on the mooring cable are the main focus of attention in this analysis. The variation of dynamic responses of the SFT under various wave conditions, water depth, and BWR (buoyancy-weight ratio) is investigated. Up to now, there is no practice project of the SFT in the world. So, the parameters of the SFT are taken from the design study conducted by $\mathrm{Oh}$ et al. [26]. At the same time, it is convenient to verify the calculation results. According to previous detailed studies on hydrodynamic coefficients by Cifuentes et al. [27], here $C_{D}$ equals to $1.2, C_{M}$ equals to 2.0, and $C_{m}$ equals to 1.0. Table 2 lists the parameter values used in this numerical experiment for comparison with the physical experiment.

By solving the governing equation of the tube movement, the time history of related physical quantities of the SFT can be obtained, including the displacement, velocity, and acceleration of the tube and mooring tension. Then the average maximum value of each physical quantity is calculated from $200 \mathrm{~s}$ to $600 \mathrm{~s}$, which the movement of the tube body has entered a stable state.

The variation of the maximum values of the horizontal and vertical motions of the tube under the wave conditions tested was calculated considering a particular BWR of 2.6 and water depth equal to $80 \mathrm{~m}$, as shown in Figure 3. The origin for horizontal and vertical motions is located at the center of the tube. From the results of Figure 3, due to the error caused by solving the linear dispersion relationship, the wavelength of the numerical simulation is slightly different from that of the experiment in the same wave period as the experiment. Therefore, at the same wave steepness as the experiment, the wave height of the numerical simulation is also slightly different from that of the experiment. $\mathrm{Nu}-$ merical simulations, on the whole, agree well with experimental data. However, when the wave height is large, the numerical simulation data will deviate from the experimental data due to the influence of nonlinear effects. For the same wave period, the horizontal and vertical displacement of the tube increases approximately linearly with the wave height increasing. For small and short waves, the response of the tube is small even considering the freedom of motion in this mode since the mooring cable does not restrict horizontal motion. However, when encountering large waves, the motion of the tube will become significant.

Figure 4 shows the horizontal and vertical displacements of the tube as a function of water depth and BWR under a particular condition that wave period is $13 \mathrm{~s}$ and wave steepness is 0.04 . In general, the results of the numerical simulation also agree with the experimental data. The dynamic response of the tube decreases with the water depth 
TABLE 2: Basic parameters of the numerical example.

\begin{tabular}{lcc}
\hline Parameter & Symbol & Values \\
\hline The tube diameter $(\mathrm{m})$ & $D$ & 23 \\
The tube length $(\mathrm{m})$ & $L$ & 98 \\
The mooring cable length $(\mathrm{m})$ & $\mathrm{H}$ & 33.1 \\
Height of pile caps $(\mathrm{m})$ & $\mathrm{H}$ & 5.5 \\
Water depth $(\mathrm{m})$ & $\mathrm{BWR}$ & $65-80-95$ \\
Buoyancy-to-weight ratio & $T$ & $2.2-2.6-3.0$ \\
Wave period $(\mathrm{s})$ & $\mathrm{s}$ & $6.5-8.0-10.0-13.0$ \\
Wave steepness & $\rho$ & $0.013-0.027-0.040-0.053$ \\
Water density $\left(\mathrm{kg} / \mathrm{m}^{3}\right)$ & $C_{D}$ & 1000 \\
Drag force coefficient & $C_{M}$ & 1.2 \\
Inertia coefficient & $C_{m}$ & 2.0 \\
Added mass coefficient & $g$ & 1.0 \\
Gravitational acceleration $\left(\mathrm{m} / \mathrm{s}^{2}\right)$ & 9.8 & 9 \\
\hline
\end{tabular}

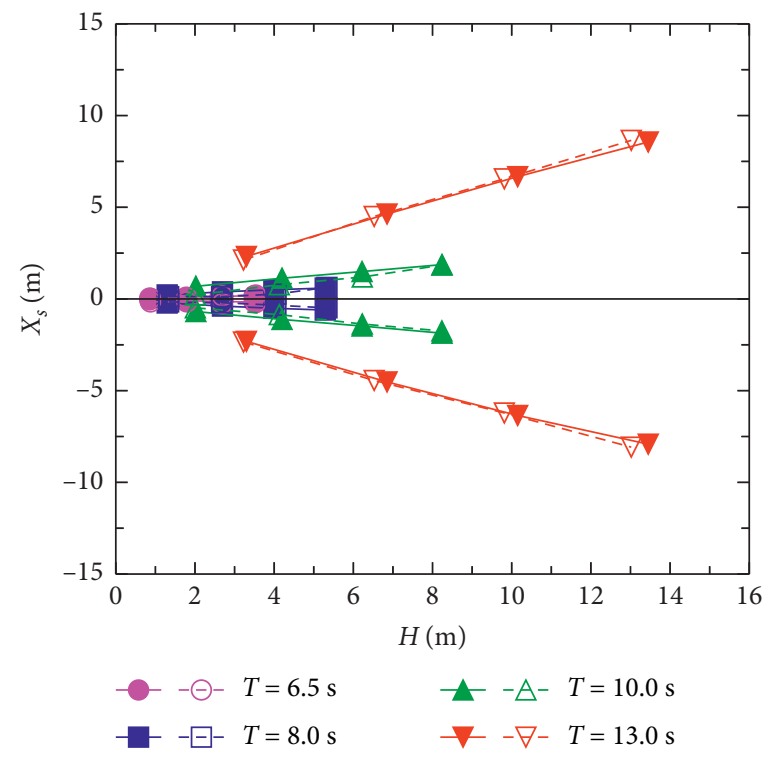

(a)

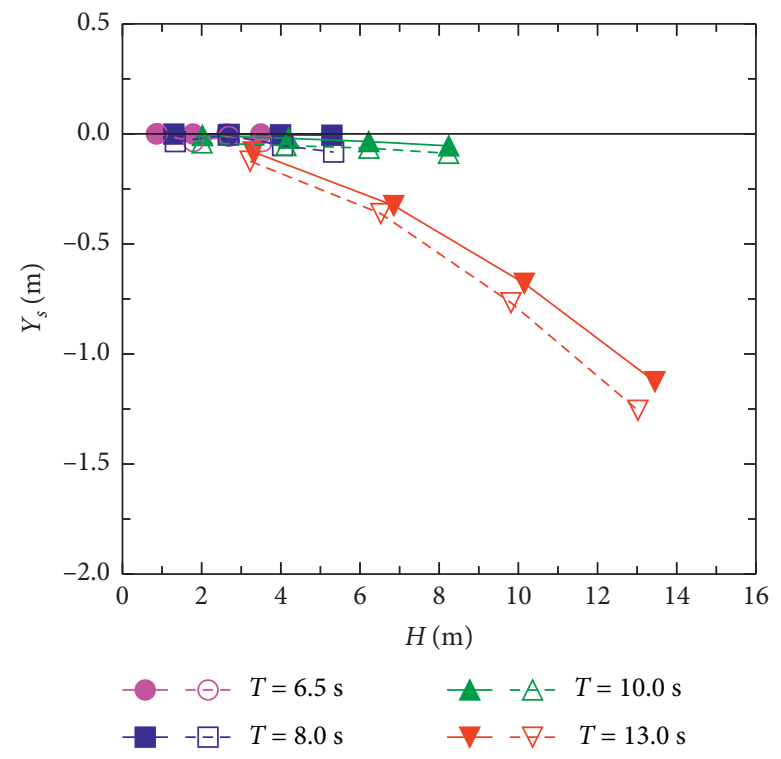

(b)

FIgURE 3: The average maximum value of (a) horizontal and (b) vertical tube displacements as a function of wave height H. Solid lines and solid markers are numerical simulation results; dotted line and open markers are experimental data.

increasing which corresponds to submergence depth increasing and increasing with the BWR increasing. Because of the error caused by the simplification of the model, there is a relatively significant deviation between the numerical simulation results and the experimental data when the water depth is small (at this time, the wave force on the tube is large). For the dynamic response of the vertical direction of the tube, there is a significant difference between the numerical simulation data and the experimental data intuitively. But this is because the displacement of the tube in the vertical direction is very small, leading to very sensitivity to the deviation of the results. In addition, when BWR is 2.2 and water depth is $80 \mathrm{~m}$, the deviation between numerical simulation results and physical experimental data is the largest, which may be due to the distortion caused by the Morison equation. The results of the numerical simulation are consistent with Cifuentes et al.'s [27] calculations using commercial finite element programs, which also use Morison equations.

Mooring cable tension is an important factor in SFT design. In this regard, the maximum and minimum tension of a single mooring cable as a function of wave period and steepness is presented in Figure 5 under BWR of 2.6 and water depth equal to $80 \mathrm{~m}$. It can be seen that the numerical simulation results are in good agreement with the experimental data. The tension of the mooring cable increases with the increase of wave period and wave steepness. The increase of both the wave period and wave steepness will lead to the increase of wave height, which can reflect the energy of the wave. Therefore, waves with huge wave height will make the dynamic response of SFT drastic. According to the above discussion, it can be verified that the numerical simulation method in this paper is accurate and effective. 


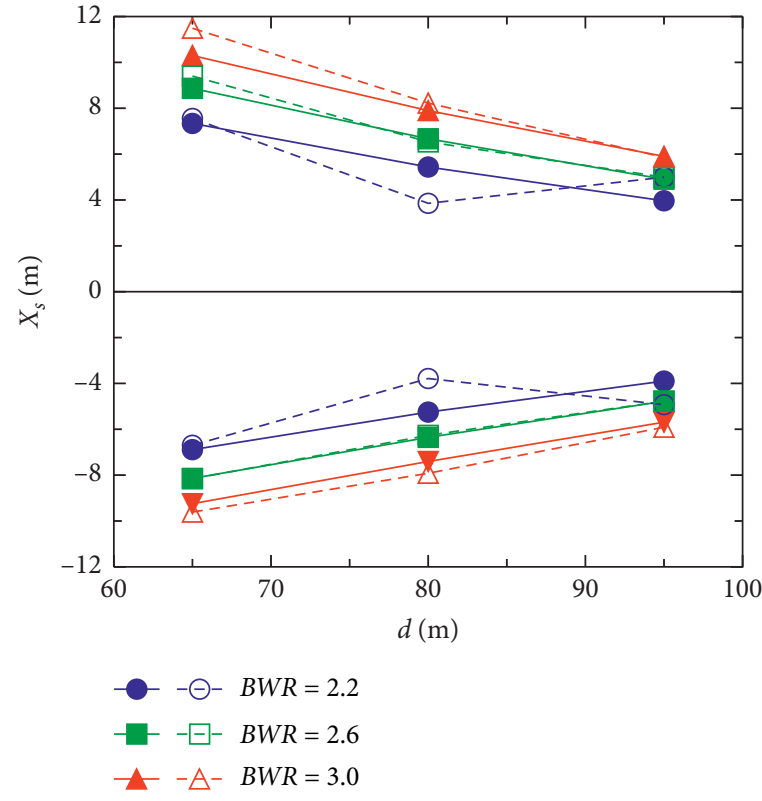

(a)

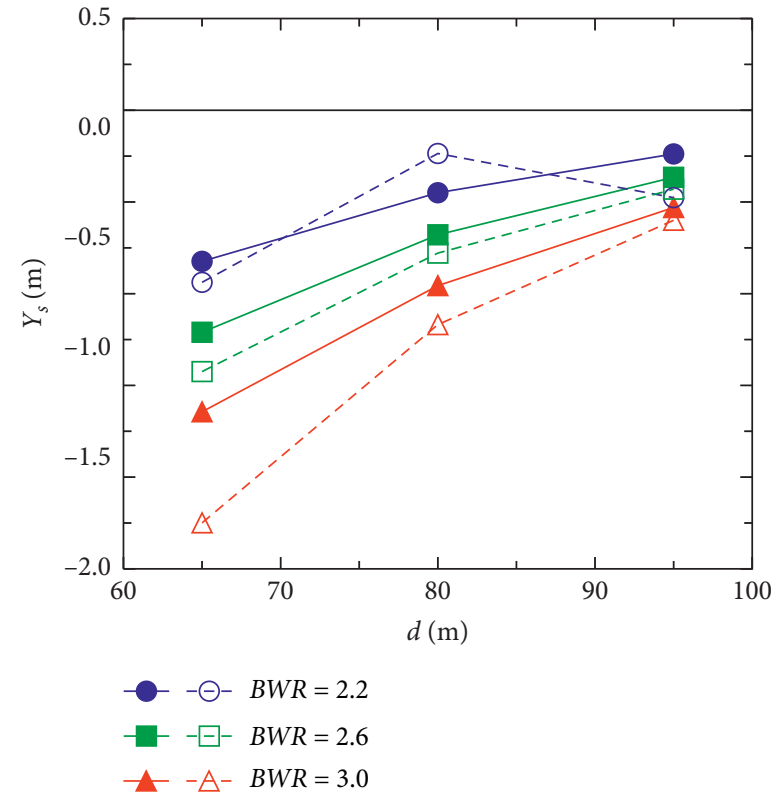

(b)

FIGURE 4: The average maximum value of (a) horizontal and (b) vertical tube displacements as a function of wave depth (d). Solid lines and solid markers are numerical simulation results; dotted lines and open markers are experimental data.

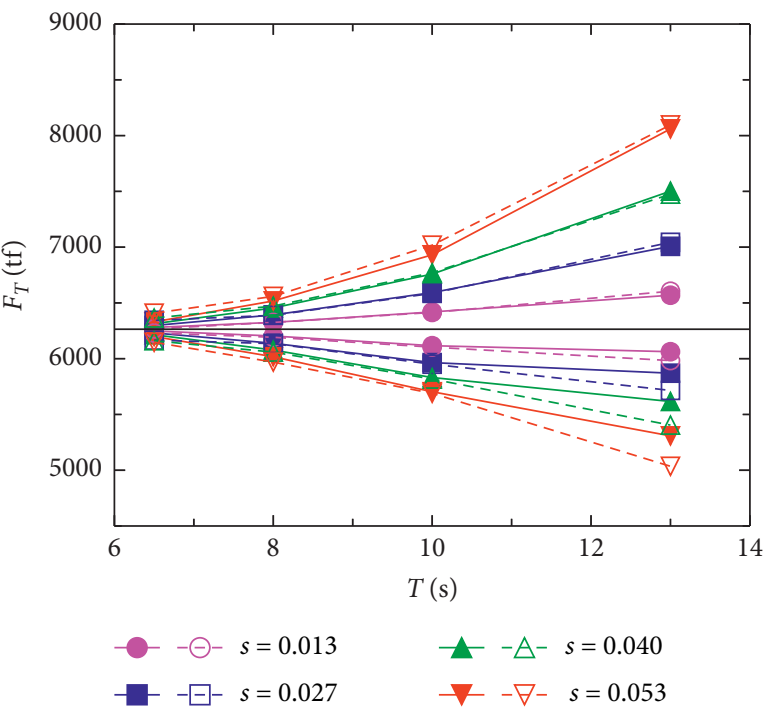

FIGURE 5: The average maximum value of tension force of a single mooring cable as a function of wave period (T). Solid lines and solid markers are numerical simulation results; dotted line and open markers are experimental data.

\section{Discussion of Influencing Parameters}

For physical experiments, they are often restricted by the cost of experiments. Therefore, the advantage of numerical experiments is that they can be repeated, efficient, and low cost to complete the simulation of physical phenomena. In the physical experiment described above, the amount of experimental data obtained is relatively small, which may not accurately reflect the changing rule of the SFT dynamic response. Because the numerical method used in this paper has the characteristics of fast calculation speed and is relatively accurate, it can continuously calculate dense data points.

5.1. Resonance of the Tunnel under Wave Force. The tension of the mooring cable is calculated as a function of the wave period by taking $0.05 \mathrm{~s}$ as a step in the wave period from $6 \mathrm{~s}$ to $13.5 \mathrm{~s}$, which is shown together with the physical experiment data in Figure 6. It is not difficult to see from Figure 6 that under the condition of constant wave steepness, the mooring cable tension increases with the increase of wave period, but the increase of mooring cable tension does not rise smoothly. When the wave period is about $8.5 \mathrm{~s}$, the mooring cable tension increases steeply and then drops, which is likely to occur resonance phenomenon under wave forces (take the wave period corresponding to the peak value of the change as the resonance period).

In order to further research the resonance phenomenon, the time history of tube displacement, anchor cable tension, and wave forces under three special wave periods and wave steepness of 0.04 are shown in Figures 7-9. In Figure 7, the wave period is $13 \mathrm{~s}$, which is much higher than the resonance period. The dynamic response of the tube reaches its maximum value shortly after the wave action begins, and soon the motion of the tube becomes stable. At this time, the horizontal wave force on the tube must be significantly smaller than the vertical wave force because the coupling effect between the horizontal motion of the tube and the horizontal wave force reduces the horizontal wave force. The vertical motion of the tube is significantly smaller than the horizontal motion, so the wave force in the vertical direction does not significantly decrease. 


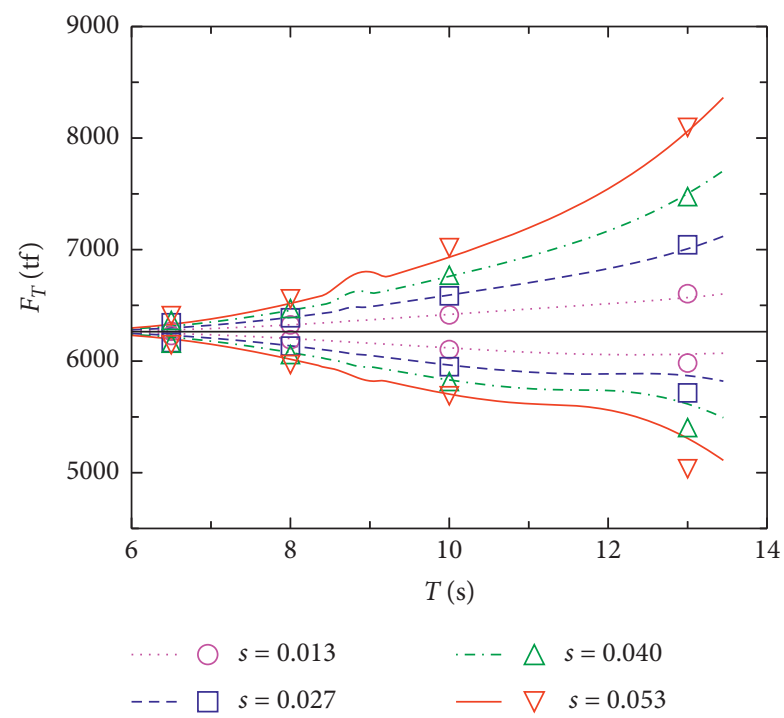

Figure 6: Tension force of a single mooring cable as a function of wave period (T). Solid lines are numerical simulation results by continuous calculation; open markers are experimental data.

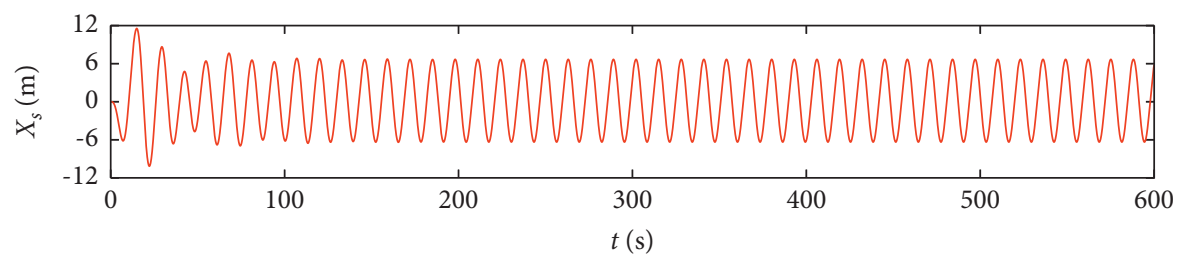

(a)

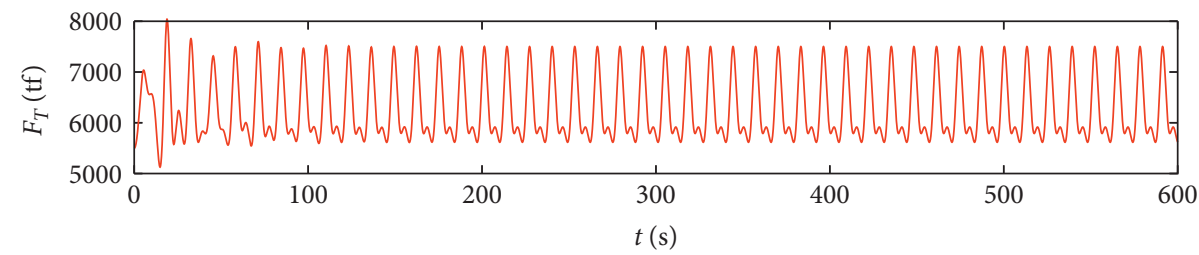

(b)

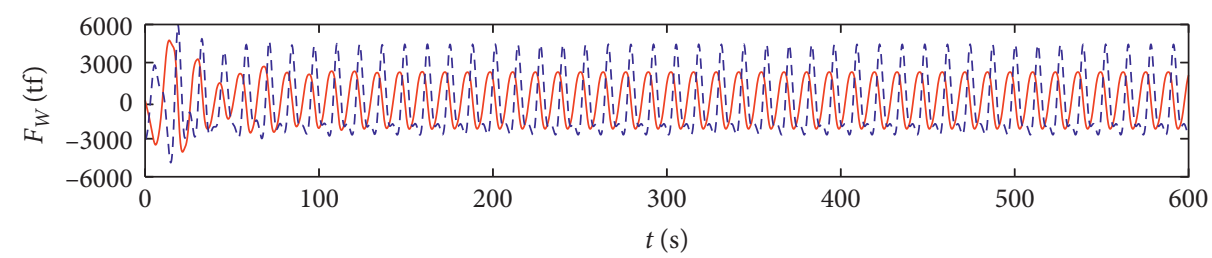

(c)

Figure 7: The time history of (a) tube displacement $X_{s}$, (b) mooring cable tension $F_{T}$, and (c) wave force $F_{W}$ (the solid line represents horizontal wave force and the dotted line represents vertical wave force) under wave period equal to $13 \mathrm{~s}$, wave steepness equal to 0.04 , and BWR equal to 2.6 .

In Figure 8, when the wave period is $9.13 \mathrm{~s}$, which is the marginal value of the period interval where the resonance occurs, the coupling effect of the motion of the tube in the horizontal direction is very obvious, so the horizontal wave force becomes extremely small. However, it can be seen from Figure 9 that when the wave period is equal to $8.75 \mathrm{~s}$ (resonance period), the coupling effect of motion of the tube in the horizontal direction will increase the horizontal wave force, and at the same time, the motion of the tube, the mooring cable tension, and the vertical wave force will also increase. After $300 \mathrm{~s}$, the movement of the tube reaches a steady state, at which point the horizontal wave force on the tube exceeds the vertical wave force. 


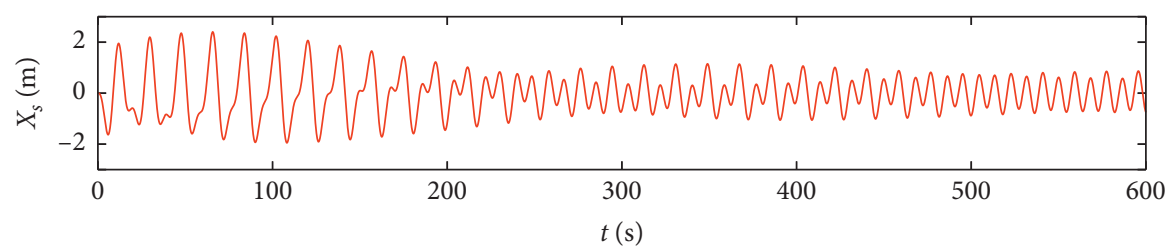

(a)

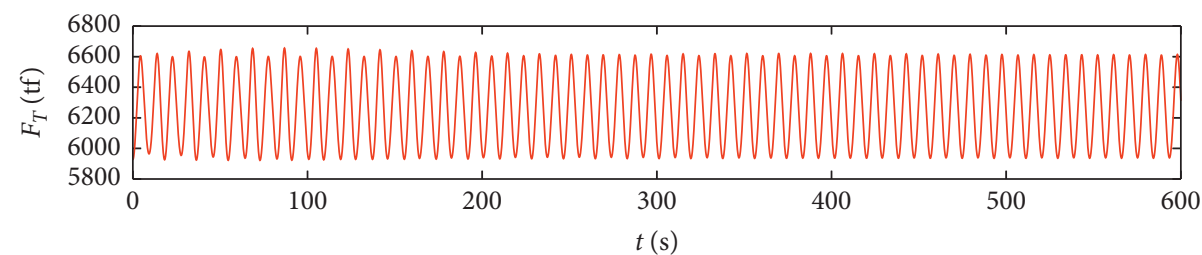

(b)

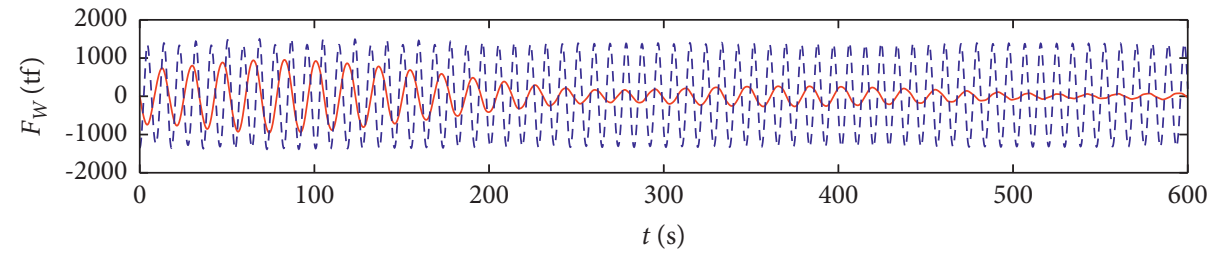

(c)

Figure 8: The time history of (a) tube displacement $X_{\mathrm{s}}$, (b) mooring cable tension $F_{T}$, and (c) wave force $F_{W}$ (the solid line represents horizontal wave force and the dotted line represents vertical wave force) under wave period equal to $9.13 \mathrm{~s}$, wave steepness equal to 0.04 , and BWR equal to 2.6.

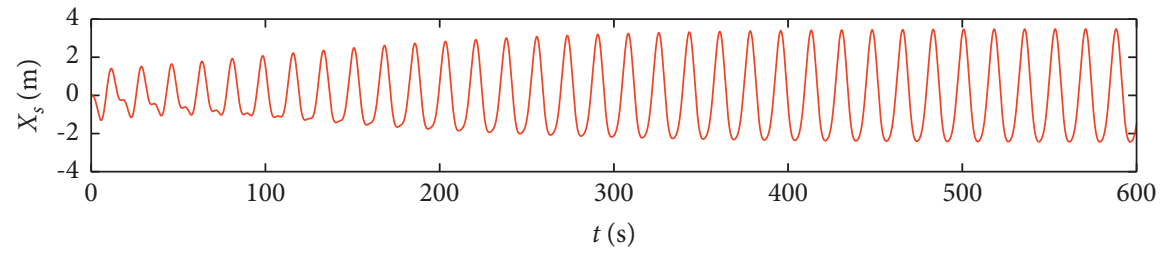

(a)

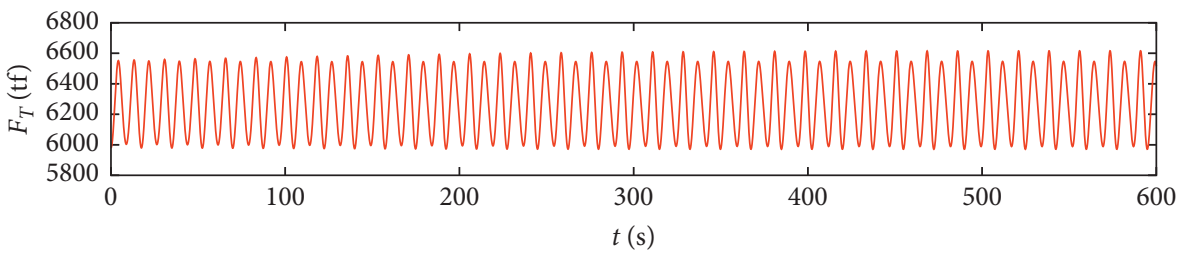

(b)

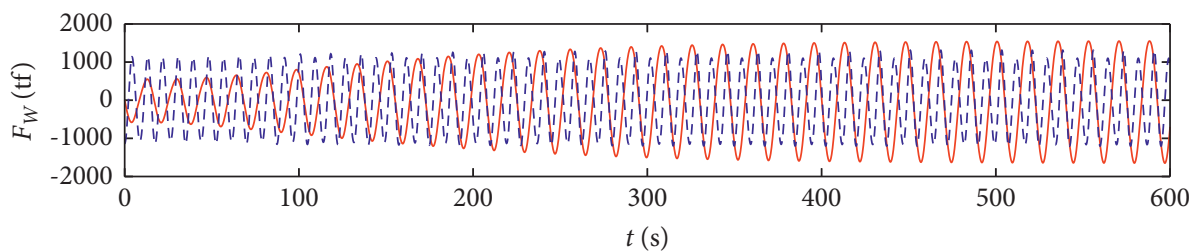

(c)

Figure 9: The time history of (a) tube displacement $X_{s}$, (b) mooring cable tension $F_{T}$, and (c) wave force $F_{W}$ (the solid line represents horizontal wave force and the dotted line represents vertical wave force) under wave period equal to $8.75 \mathrm{~s}$, wave steepness equal to 0.04 , and BWR equal to 2.6 . 


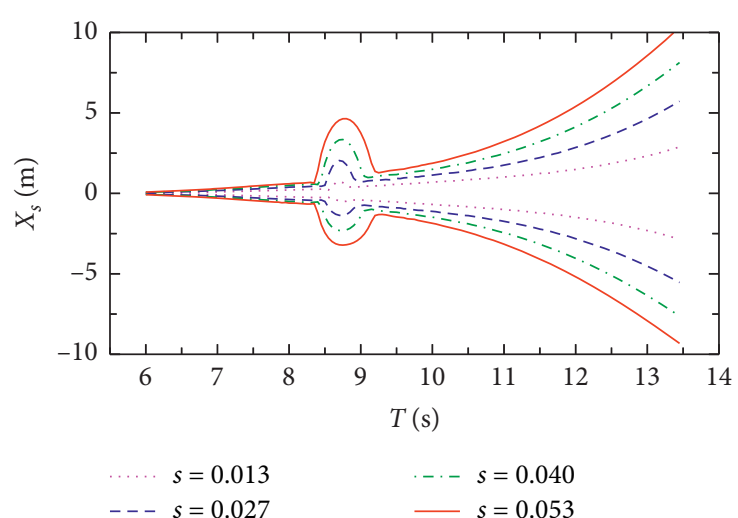

(a)

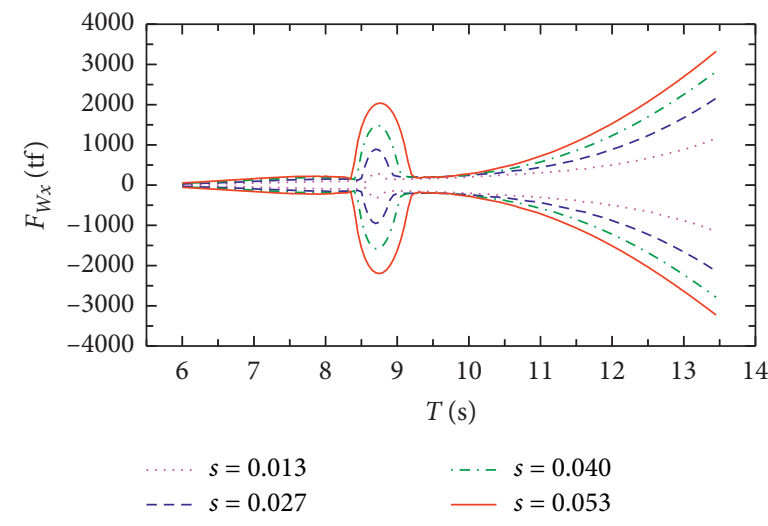

(c)

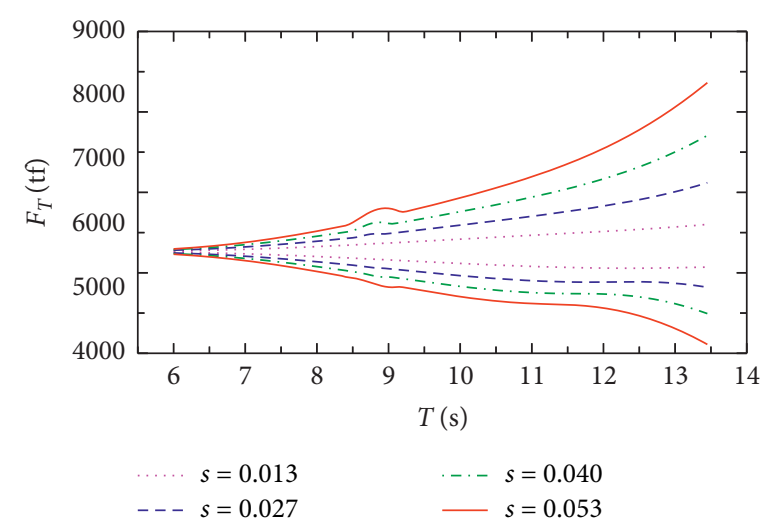

(b)

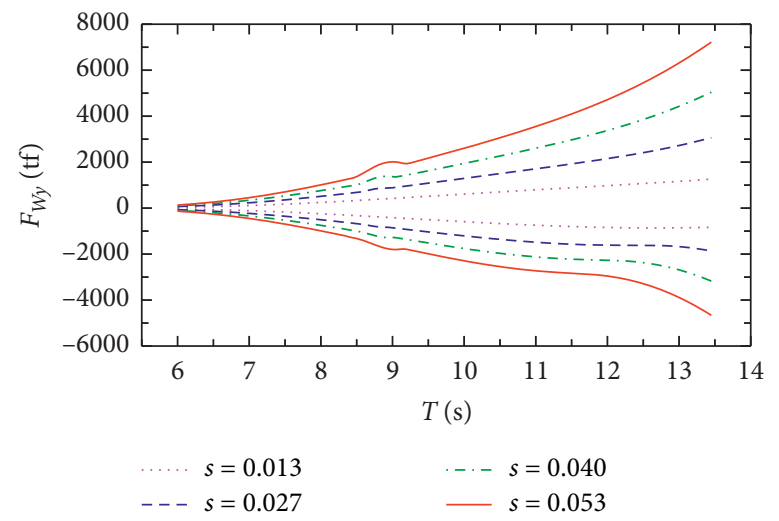

(d)

Figure 10: Relevant physical quantities are changed by various wave periods $T$ with different wave steepness (s): (a) the horizontal displacement of the tube $X_{s}$, (b) the mooring cable tension $F_{T}$, (c) the horizontal wave forces $F_{W x}$, and (d) the vertical wave forces $F_{W y}$ $(\mathrm{BWR}=2.6 ; d=80 \mathrm{~m})$.

5.2. Influence Factor for the Resonance Period. According to the above analysis, when the resonance phenomenon occurs, the horizontal vibration of the tube will not reduce the horizontal wave force it receives, but increase the horizontal wave force, so that the dynamic response of the tube will also increase. This may seriously threaten the safety of the structure. If the resonance period is revealed, some wave absorption or reflector devices can be used to avoid wave action with the resonance period on the structure. Therefore, it is necessary to further explore the wave period corresponding to the resonance of the structure.

Relevant physical quantities are changed by various wave periods with different wave steepness and water depths, which are shown in Figures 10 and 11. In addition to the mooring cable tension, the movement of the tube and the wave force on the tube will also increase suddenly in the same specific wave period. Although the dynamic response of the tube will increase when the wave steepness increases or the water depth decreases, it does not affect the position of the resonance period. But when the wave height increases or the water depth decreases, the position of the resonance period will be slightly deviated due to the influence of nonlinear factors.

When the BWR is 2.2, 2.6, 3.0, and 3.4, respectively, relevant physical quantities are changed by various wave periods, as shown in Figure 12. The increase of the BWR will increase the motion of the tube and mooring cable tension, which is consistent with the results of the physical experiment. However, when the tube resonates, the dynamic response of the tube increases with the BWR decreasing. At the same time, the BWR significantly affects the resonance period. The resonance period also increases with the BWR decreasing. In other words, when the BWR of the tube is small, it should be avoided as much as possible that the resonance caused by long-period wave action on the structure.

Under the condition that the water depth and submergence depth remain unchanged by changing mooring cable length and height of pile caps at the same time, relevant physical quantities are changed by various wave periods, as shown in Figure 13. With the increase of wave period to about $10 \mathrm{~s}$, the increasing speed of the dynamic response of the tube with a shorter mooring cable is obviously higher than that of the tube with a longer mooring cable. This is because when the mooring cable is short, the increase of the horizontal motion of the tube will significantly increase the vertical motion of the tube (compared with that when the mooring cable is long), so that the coupling effect of vertical motion and vertical wave force is strengthened, which further increases the dynamic response of the SFT. Similarly, 


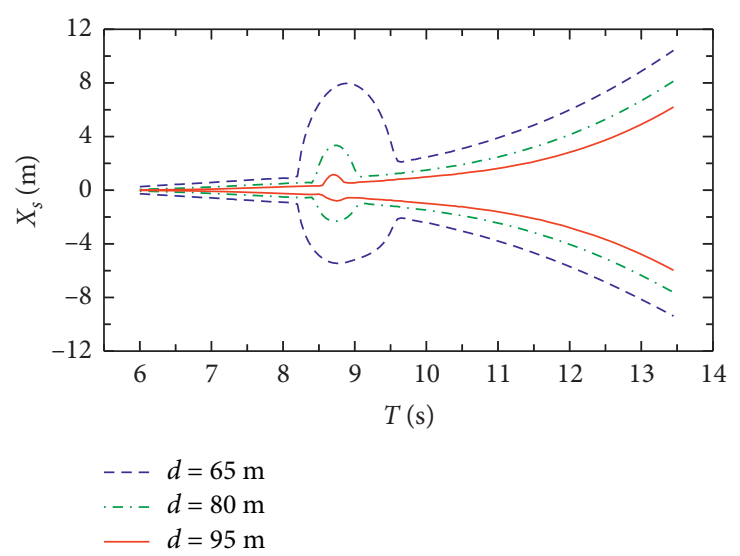

(a)

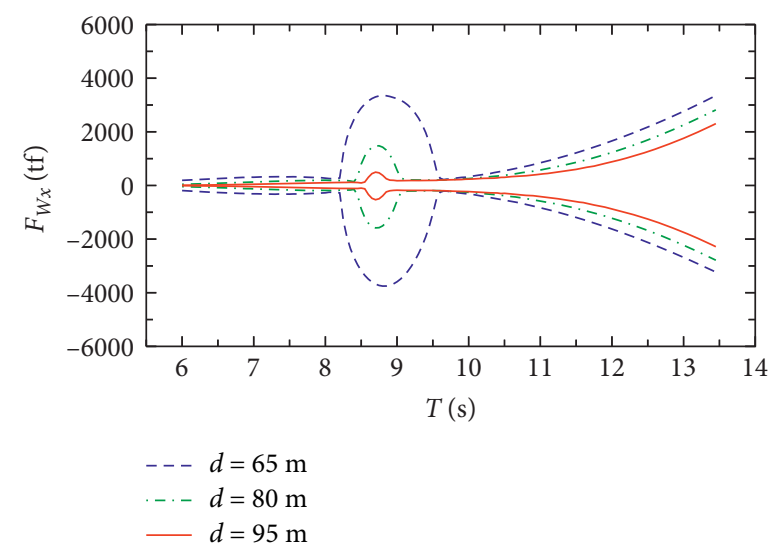

(c)

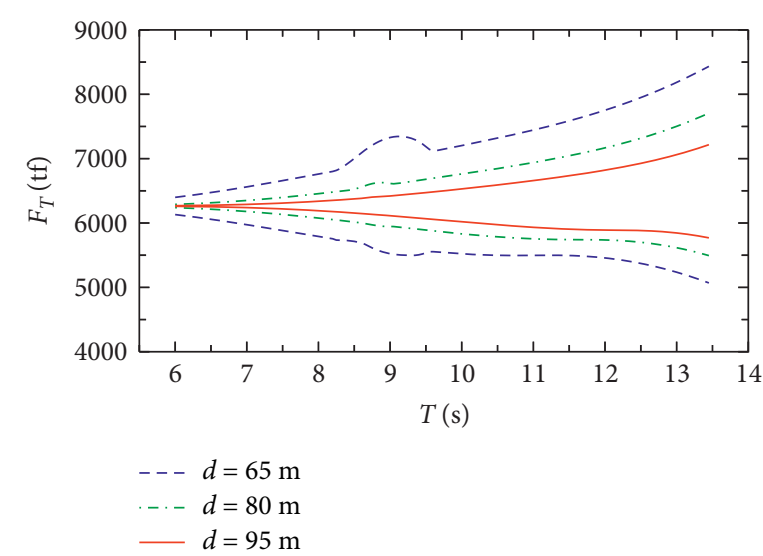

(b)

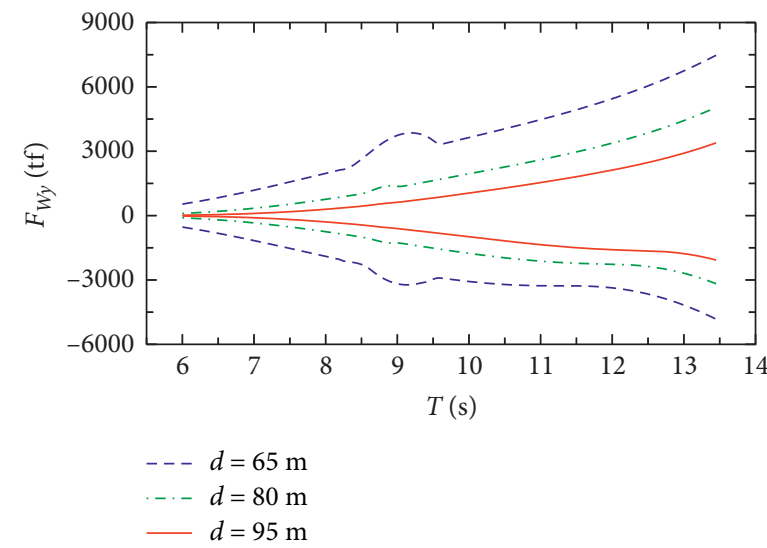

(d)

Figure 11: Relevant physical quantities are changed by various wave periods $T$ with different water depths (d): (a) the horizontal displacement of the tube $X_{s}$, (b) the mooring cable tension $F_{T}$, (c) the horizontal wave forces $F_{W X}$, and (d) the vertical wave forces $F_{W y}(s=0.04 ;$ BWR $=2.6)$.

the mooring cable length is also an important parameter affecting the resonance period. Both the resonance period and the dynamic response of the tube at the tube resonating increase with the cable length increases.

It is not difficult to see from Figure 10 to 13 that the change law of horizontal displacement of the tube is similar to the change law of horizontal wave force, and the change law of mooring cable tension is similar to the change law of vertical wave force. This may be due to the coupling between the motion state of the tube and the wave force.

5.3. Estimation of the Resonance Period. According to the above discussion, the value of the resonance period is related to the BWR and the mooring cable length but independent of the water depth and the wave steepness. The BWR and mooring cable length are the influencing factors of the natural vibration period of the tube. Based on the assumptions of this mathematical model, the natural vibration period of the tube can be calculated by the period formula of a single pendulum shown in (15). The natural vibration periods of different BWR and mooring cable lengths can be calculated by this formula. The calculated results are shown in Table 3 together with the resonant period of the structure.

$$
T_{n}=2 \pi \sqrt{\frac{l}{g(\mathrm{BWR}-1)}} .
$$

It can be seen from Table 3 that the resonance period of the tube body is not exactly equal to its natural vibration period. When the length of the mooring cable changes, the ratio of the resonance period of the tube to the natural vibration period changes very little, but when the BWR changes, the ratio changes obviously, and the change belongs to the linear trend. Therefore, the estimation formula of resonance period can be obtained by linear fitting of the data:

$$
T_{r}^{*}=(0.779 \times B W R+3.968) \sqrt{\frac{l}{g(B W R-1)}} .
$$

The resonance periods calculated by Equation (16) and the numerical simulation results are shown in Figure 14. The results calculated by the estimation formula agree with those of numerical simulation. According to (16), when the mooring cable length is $20 \mathrm{~m}$ and the BWR is 1.5 , the resonance period is $10.5 \mathrm{~s}$. For small rivers or lakes, waves with periods longer than $10 \mathrm{~s}$ are hard to come, which means that resonance is difficult to occur as long as the BWR of SFT with 


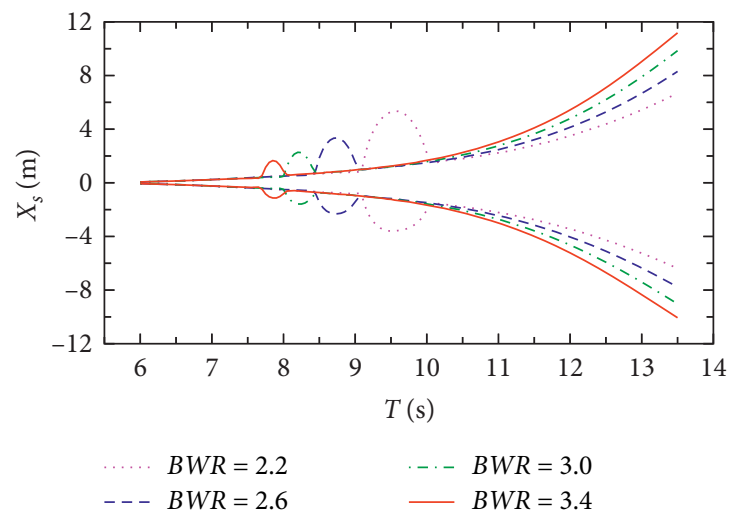

(a)

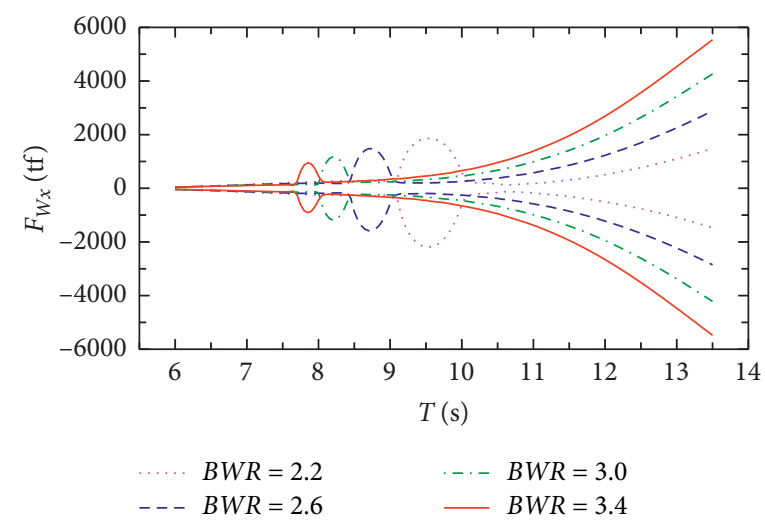

(c)

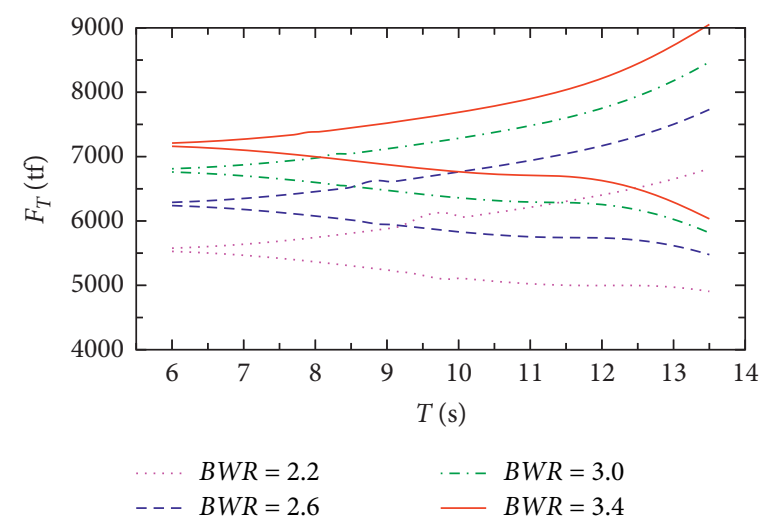

(b)

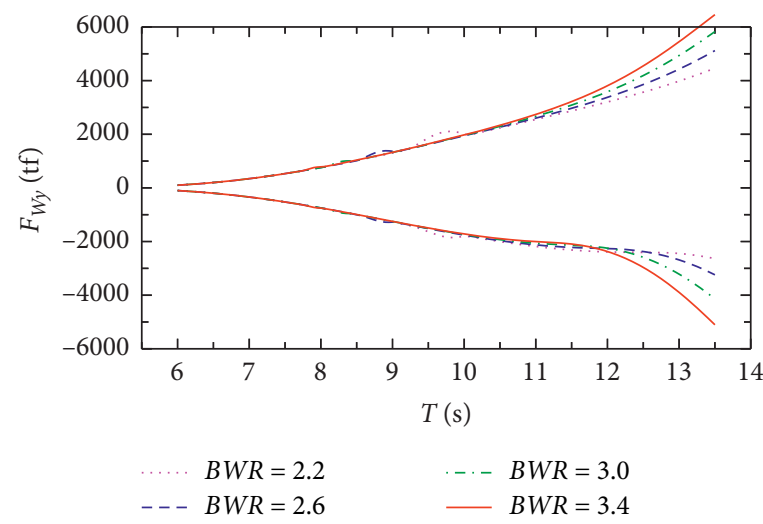

(d)

FIGURE 12: Relevant physical quantities are changed by various wave periods $T$ with different BWR: (a) the horizontal displacement of the tube $X_{s}$, (b) the mooring cable tension $F_{T}$, (c) the horizontal wave forces $F_{W x}$, and (d) the vertical wave forces $F_{W y}(s=0.04 ; d=80 \mathrm{~m}$ ).

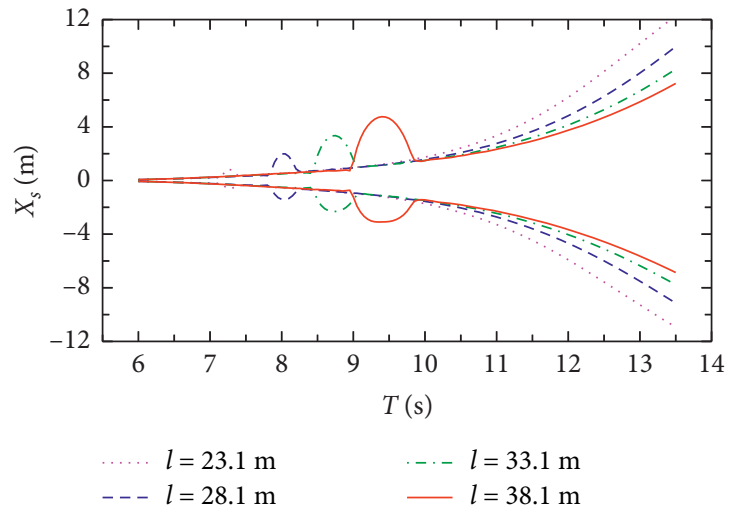

(a)

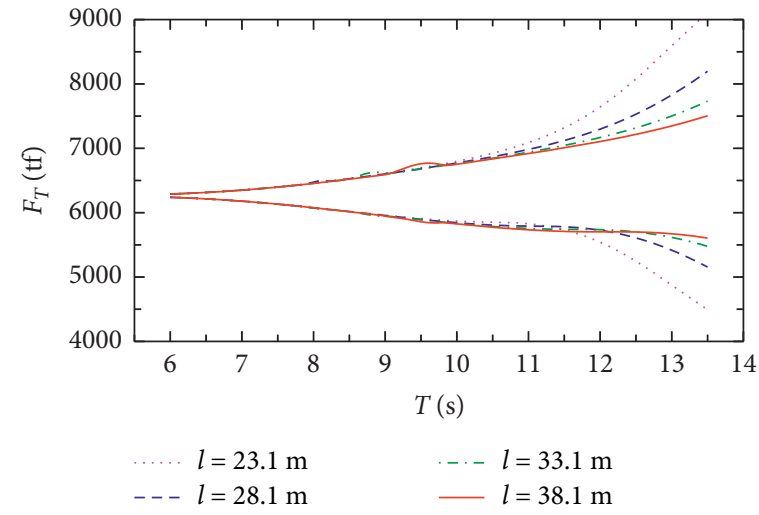

(b)

FIgURE 13: Continued. 


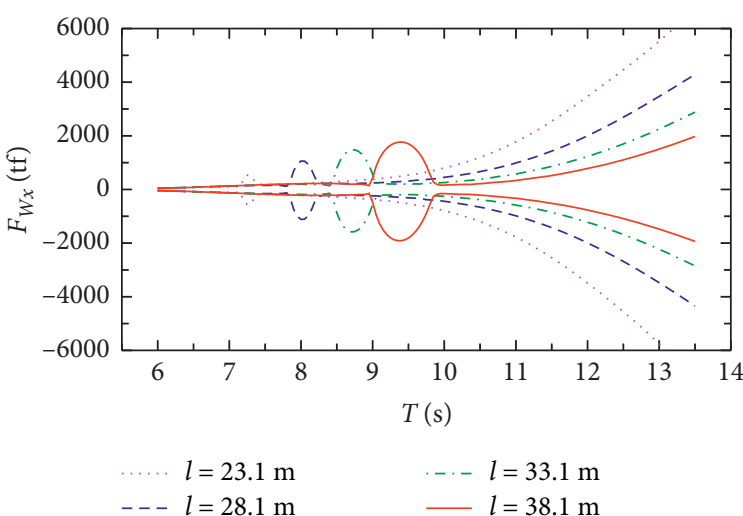

(c)

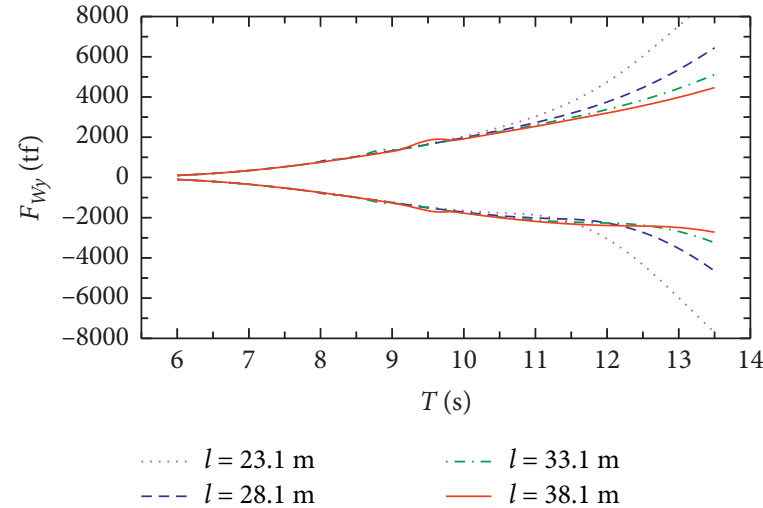

(d)

Figure 13: Relevant physical quantities are changed by various wave periods T with different lengths of mooring cable (l): (a) the horizontal displacement of the tube $X_{s}$, (b) the mooring cable tension $F_{T}$, (c) the horizontal wave forces $F_{W x}$, and (d) the vertical wave forces $\mathrm{F}_{\mathrm{Wy}}$ $(s=0.04, \mathrm{BWR}=2.6 ; d=80 \mathrm{~m})$.

TABLE 3: The resonant period and natural vibration period of the tube.

\begin{tabular}{|c|c|c|c|c|}
\hline BWR & Mooring cable length $l(\mathrm{~m})$ & Resonance period $T_{r}(\mathrm{~s})$ & Natural vibration period $T_{n}(\mathrm{~s})$ & $T_{r} / T_{n}$ \\
\hline 1.8 & 33.1 & 11.15 & 12.91 & 0.864 \\
\hline 2.2 & 33.1 & 9.55 & 10.54 & 0.906 \\
\hline 2.6 & 33.1 & 8.75 & 9.13 & 0.958 \\
\hline 3.0 & 33.1 & 8.20 & 8.17 & 1.004 \\
\hline 3.4 & 33.1 & 7.85 & 7.45 & 1.053 \\
\hline 2.6 & 23.1 & 7.25 & 7.63 & 0.951 \\
\hline 2.6 & 28.1 & 8.00 & 8.41 & 0.951 \\
\hline 2.6 & 33.1 & 8.75 & 9.13 & 0.958 \\
\hline 2.6 & 38.1 & 9.4 & 9.79 & 0.960 \\
\hline
\end{tabular}

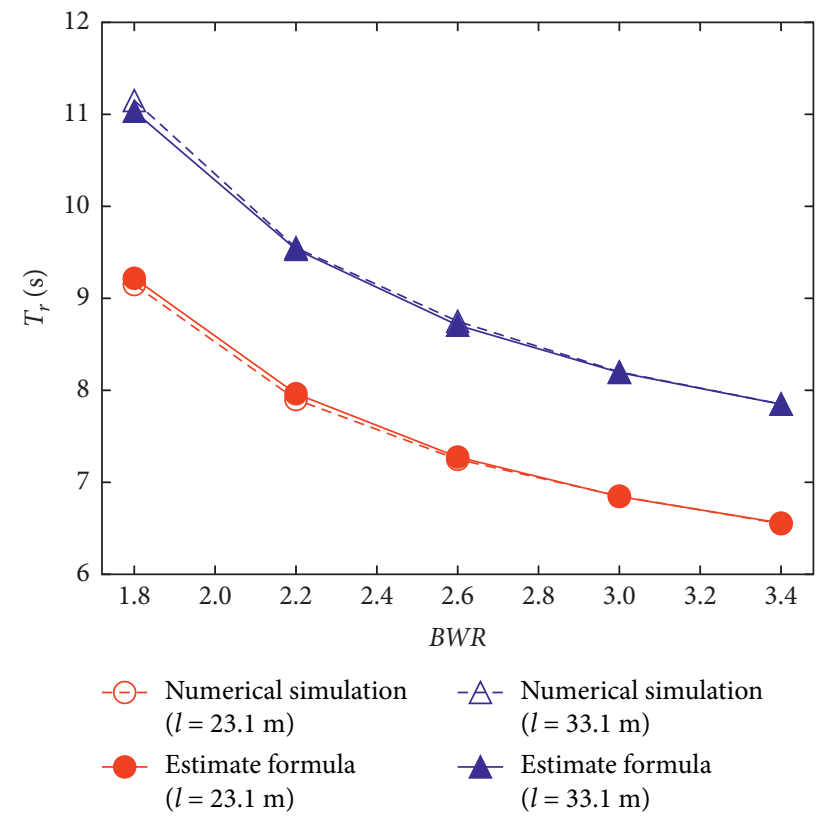

FIGURE 14: Comparison of estimation formula with numerical simulation of resonance period. 
vertical mooring cable is controlled within 1.5. However, in the ocean environment, if resonance is not effectively avoided, the structure is difficult to ensure its safety.

\section{Conclusions}

This study discusses the dynamic response of a tunnel with vertical mooring cable under regular waves. The main conclusions in this study show the following:

(1) The dynamic response of the tube calculated by the proposed analytical method approximately tends to follow a linear variation as the wave height and water depth increase, which is consistent with the experimental data.

(2) Under the condition of keeping the wave steepness constant, the increase of wave period will increase the dynamic response of the tube. However, when the wave period does not exceed $8.5 \mathrm{~s}$, the dynamic response of the tube is linear with the wave period. When the wave period exceeds $11 \mathrm{~s}$, the relationship between the dynamic response and the wave is nonlinear. But, when the wave period changes to a certain interval, the dynamic response of the tube will suddenly and greatly increase. In the interval of this wave period, the tube body resonates under the action of wave force.

(3) The value of the resonance period of the tube is mainly related to the BWR and the mooring cable length. On the one hand, the resonance period increases with BWR decreasing. At the same time, when the tube resonates, the dynamic response of the tube also increases with the BWR decreasing. On the other hand, both the resonance period and the dynamic response of the tube at the tube resonating increase with the cable length increases.

(4) In general, the dynamic response of the tube is very violent at the initial stage of the wave loading, and then the dynamic response of the tube will gradually decrease until the motion state of the tube is stable. However, when the tube resonates, the dynamic response of the tube will gradually increase until the motion state of the tube is stable. This may be due to the increasing horizontal wave force of the tube when resonance occurs.

(5) The estimation formula of wave period corresponding to tunnel resonance is proposed in this paper. This formula can estimate the value of the resonance period relatively accurately in a certain range. It can be seen from the formula that for small rivers or lakes, the resonance is generally difficult to occur as long as the cable length exceeds $20 \mathrm{~m}$ and the BWR is lower than 1.5. Therefore, the formula can provide a reference for the determination of the SFT design parameters to avoid the occurrence of resonance.

(6) Although the vertical layout of the mooring cable can effectively reduce the tension of the mooring cable, it also makes the tube body lack the horizontal direction constraint, resulting in very large displacement, and even resonance may occur due to the action of wave force. Therefore, the vertical arrangement of the mooring cables is only suitable for the SFT with a small span. Obviously, the inclined layout of the mooring cable can greatly reduce the movement of the tube. A larger BWR and opening angle of the mooring cable will increase the cable tension, but it will also make the tube more stable.

Overall, although there are still many technical difficulties in the submerged floating tunnel, it is undeniable that the SFT is still a feasible and valuable concept. It can be seen that with the development of science and technology, these technical problems will be solved one by one. Further analysis including nonlinear vortex-induced vibrations, coupled wave-seismic action, vehicle-tunnel coupled vibration responses, and so on is needed to provide a complete set of data for the successful design of the SFT structure.

\section{Data Availability}

The data used to support the findings of this study are available from the corresponding author upon request.

\section{Conflicts of Interest}

The authors declare that there are no conflicts of interest regarding the publication of this study.

\section{Acknowledgments}

The authors are grateful for the support of this research by the National Key Research and Development Program (2019YFB1600700), the National Natural Science Foundation of China (51978600 and 52008065), the Chongqing Municipal Education Commission Science and Technology Research Project (KJQN202000706), the Postdoctoral Research Foundation of China (2020M683229), the Venture and Innovation Support Program for Chongqing Overseas Returnees (cx2020104), the General Project of Chongqing Natural Science Foundation (cstc2021jcyj-msxmX1082, cstc2019jcyj-msxmX0583), the Key Project of National Key Research and Development Project (2016YFC0802206-3), the Program for Innovation Team Building at Institutions of Higher Education in Chongqing (CXQT19021), and the High-Level Technical Personnel Training Project of Transportation Industry.

\section{References}

[1] L. Xu, F. Ge, L. Wang, and Y. Hong, "Effects of fundamental structure parameters on dynamic responses of submerged floating tunnel under hydrodynamic loads," Acta Mechanica Sinica, vol. 10, no. 3, pp. 335-344, 2009.

[2] Y. Xiang, Z. Chen, Y. Yang, H. Lin, and S. Zhu, "Dynamic response analysis for submerged floating tunnel with anchorcables subjected to sudden cable breakage," Marine Structures, vol. 59, no. 5, pp. 179-191, 2018. 
[3] H. Østlid, "When is SFT competitive," Procedia Engineering, vol. 4, no. 1877, pp. 3-11, 2010.

[4] Y. Q. Xiang, Z. Y. Chen, and Y. Yang, "Research development of method and simulation for analyzing dynamic response of submerged floating tunnel," China Journal of Highway and Transport, vol. 30, no. 1, pp. 69-76, 2017.

[5] C. Hakkart, "State of the art (international tunnelling association)," in Proceedings of the International Conference on Submerged Floating Tunnels, Vegdirektoratet, Sandnes, Norway, 1996.

[6] D. Ahrens, "Chapter 10 submerged floating tunnels-a a concept whose time has arrived," Tunnelling and Underground Space Technology, vol. 12, no. 2, pp. 2317-2336, 1997.

[7] Y. Hong and F. Ge, "Dynamic response and structural integrity of submerged floating tunnel due to hydrodynamic load and accidental load," Procedia Engineering, vol. 4, pp. 35-50, 2010.

[8] F. M. Mazzolani, R. Landolfo, B. Faggiano, M. Esposto, F. Perotti, and G. Barbella, "Structural analyses of the submerged floating tunnel prototype in Qiandao lake (PR of China)," Advances in Structural Engineering, vol. 11, no. 4, pp. 439-454, 2008.

[9] Y. Xiang and Y. Yang, "Spatial dynamic response of submerged floating tunnel under impact load," Marine Structures, vol. 53, pp. 20-31, 2017.

[10] H. Lin, Y. Xiang, and Y. Yang, "Vehicle-tunnel coupled vibration analysis of submerged floating tunnel due to tether parametric excitation," Marine Structures, vol. 67, no. 9, p. 102646.1, 2019.

[11] M. Sato, S. Kanie, and T. Mikami, "Mathematical analogy of a beam on elastic supports as a beam on elastic foundation," Applied Mathematical Modelling, vol. 32, no. 5, pp. 688-699, 2008.

[12] M. Di Pilato, F. Perotti, and P. Fogazzi, "3D dynamic response of submerged floating tunnels under seismic and hydrodynamic excitation," Engineering Structures, vol. 30, no. 1, pp. 268-281, 2008.

[13] L. Martinelli, G. Barbella, and A. Feriani, "A numerical procedure for simulating the multi-support seismic response of submerged floating tunnels anchored by cables," Engineering Structures, vol. 33, no. 10, pp. 2850-2860, 2011.

[14] L. Martinelli, M. Domaneschi, and C. Shi, "Submerged floating tunnels under seismic motion: vibration mitigation and seaquake effects," Procedia Engineering, vol. 166, 2016.

[15] Z. Wu and G. Mei, "Dynamic response analysis of cable of submerged floating tunnel under hydrodynamic force and earthquake," Shock and Vibration, vol. 2017, Article ID 3670769, 14 pages, 2017.

[16] J. Xie and J. Chen, "Dynamic response analysis of submerged floating tunnel - canyon water system under earthquakes," Applied Mathematical Modelling, vol. 94, no. 10, pp. 757-779, 2021.

[17] S.-n. Sun and Z.-b. Su, "Parametric vibration of submerged floating tunnel tether under random excitation," China Ocean Engineering, vol. 25, no. 2, pp. 349-356, 2011.

[18] S. Sun, Z. Su, Y. Feng, and Y. S. Xian, "Parametric vibration analysis of submerged floating tunnel tension legs," China Ocean Engineering, vol. 34, no. 1, p. 6, 2020.

[19] S.-i. Seo, M. Sagong, and S.-w. Son, "Global response of submerged floating tunnel against underwater explosion," Ksce Journal of Civil Engineering, vol. 19, no. 7, pp. 2029-2034, 2015.
[20] Y. Xiang, C. Liu, K. Zhang, and Q. Wu, "Risk analysis and management of submerged floating tunnel and its application," Procedia Engineering, vol. 4, no. 1, pp. 107-116, 2010.

[21] W. Lu, F. Ge, L. Wang, X. Wu, and Y. Hong, "On the slack phenomena and snap force in tethers of submerged floating tunnels under wave conditions," Marine Structures, vol. 24, no. 4, pp. 358-376, 2011.

[22] C. Jin and M. H. Kim, "Tunnel-mooring-train coupled dynamic analysis for submerged floating tunnel under wave excitations," Applied Ocean Research, vol. 94, pp. 1-17, 2020.

[23] G. Luo, S. Pan, Y. Zhang, and L. Chen, "Response analysis of submerged floating tunnel hit by submarine based on smoothed-particle hydrodynamics," Shock and Vibration, vol. 2019, Article ID 9056416, 12 pages, 2019.

[24] H. Kunish, "Evaluation of wave force acting on submerged floating tunnels," Procedia Engineering, vol. 4, pp. 99-105, 2010.

[25] C. Chao, Dynamic Response Analysis and experiment of Submerged Floating Tunnel Based on Fluid-Structure Interaction,"Doctor's Thesis, Zhejiang University, Hangzhou, 2016.

[26] S. H. Oh, W. S. Park, S. C. Jang, D. H. Kim, and H. D. Ahn, "Physical experiments on the hydrodynamic response of submerged floating tunnel against the wave action," in Proceedings of the 7th International Conference on Asian and Pacific Coasts, pp. 24-26, Hasanuddin University Press, Bali, Indonesia, Sept 2013.

[27] C. Cifuentes, S. Kim, M. H. Kim, and W. S. Park, "Numerical simulation of the coupled dynamic response of a submerged floating tunnel with mooring lines in regular waves," Ocean Systems Engineering, vol. 5, no. 2, pp. 109-123, 2015.

[28] Z. Yang, J. Li, H. Zhang, C. Yuan, and H. Yang, "Experimental study on $2 \mathrm{~d}$ motion characteristics of submerged floating tunnel in waves," Journal of Marine Science and Engineering, vol. 8, no. 2, p. 123, 2020.

[29] S.-i. Seo, H.-s. Mun, J.-h. Lee, and J.-h. Kim, "Simplified analysis for estimation of the behavior of a submerged floating tunnel in waves and experimental verification," Marine Structures, vol. 44, no. 12, pp. 142-158, 2015.

[30] I. Y. Paik, C. K. Oh, J. S. Kwon, and S. P. Chang, "Analysis of wave force induced dynamic response of submerged floating tunnel," KSCE Journal of Civil Engineering, vol. 8, no. 5, pp. 543-550, 2004.

[31] F. Ge, W. Lu, X. Wu, and Y. Hong, "Fluid-structure interaction of submerged floating tunnel in wave field," Procedia Engineering, vol. 4, no. 4, pp. 263-271, 2010.

[32] X. Chen, Q. Chen, Z. Chen, and S. Cai, "Numerical modeling of the interaction between submerged floating tunnel and surface waves," Ocean Engineering, vol. 220, p. 16, Article ID 108494, 2021.

[33] P. X. Zou, J. D. Bricker, and W. S. J. Uijttewaal, "The impacts of internal solitary waves on a submerged floating tunnel," Ocean Engineering, vol. 238, p. 15, Article ID 109762, 2021.

[34] J. F. Wilson, Dynamics of Offshore Structurep. 25, 2rd ed edition, John Wiley \& Sons, Hoboken, United States, 2003.

[35] Y. Xiang and K. Zhang, "The layered integrating method for calculating wave force of submerged floating tunnel based on Mo-rison equation," Journal of Zhejiang University (Engineering Science), vol. 45, no. 8, pp. 1399-1404, 2011. 